\title{
NARRATIVAS DO CUIDADO A CRIANÇAS EM UM NASF: A ESTRATÉGIA RODINHA DE CONVERSA
}

\author{
NARRATIVAS DE CUIDADO PARA NIÑOS EN UN NASF: \\ LA ESTRATEGIA RUEDA DE CONVERSACIÓN \\ NARRATIVES OF CARE FOR CHILDREN IN A NASF: \\ THE CONVERSATION WHEEL STRATEGY
}

\section{Allana Rodrigues Alaion ${ }^{1}$ e Adriana Marcondes Machado ${ }^{1}$}

${ }^{1}$ Universidade de São Paulo, São Paulo/SP, Brasil

RESUMO: Em um território permeado por situações de vulnerabilidade social, as demandas de saúde mental dos adultos carregam desafios em relação às infâncias vividas nas famílias, convocando um Núcleo de Apoio à Saúde da Família (NASF) em um município da Baixada Santista a se debruçar sobre isto. Esse trabalho refere-se a uma pesquisaintervenção realizada a partir da atuação de uma psicóloga nesse NASF para acolher as demandas de saúde mental infantil, sendo desenvolvida uma estratégia denominada Rodinha de Conversa. Como recurso metodológico foram utilizados diários de campo e construídas narrativas como forma de dar visibilidade a histórias vividas, ao território e à estratégia de trabalho desenvolvida. As Rodinhas de Conversa serviram como analisadoras do funcionamento da rede de serviços e dos fluxos nos trabalhos da atenção básica, e romperam uma lógica diagnóstica de triagem.

PALAVRAS-CHAVE: Núcleo de Apoio à Saúde da Família; Narrativas; Trabalho em Saúde; Psicologia; Infâncias.

RESUMEN: En un territorio impregnado por situaciones de vulnerabilidad social, las exigencias de salud mental de los adultos conllevan desafíos en relación a las infancias vividas con sus familias, llamando a un Centro de Apoyo a la Salud de la Familia (NASF) en un municipio de la Baixada Santista para atender este tema. Este trabajo hace referencia a una investigación-intervención realizada desde el trabajo de una psicóloga en este NASF para atender las demandas de la salud mental infantil, en la que fue desarrollada una estrategia denominada Rueda de Conversación. Como recurso metodológico, se utilizaron diarios de campo y se construyeron narrativas como una forma de dar visibilidad a las historias vividas, el territorio y la estrategia de trabajo desarrollada. Las Ruedas de Conversación sirvieron como analizadores del funcionamiento de la red de servicios y los flujos en los trabajos de atención primaria, y rompieron una lógica diagnóstica de clasificación.

PALABRAS CLAVE: Centro de Apoyo a la Salud de la Familia; Narrativas; Trabajo en Salud; Psicología; Infancias.

ABSTRACT: In a territory permeated by situations of social vulnerability, the mental health demands of adults carry challenges in relation to the childhoods lived in their families, calling a Family Health Support Center (NASF) in a municipality in Baixada Santista to address this issue. This paper refers to a research-intervention carried out from the role of a psychologist in this NASF to meet the demands of child mental health, with a strategy called Wheel of Conversation being developed. As a methodological resource, field diaries were used and narratives were constructed as a way of giving visibility to the stories, the territory and the work strategy developed. The Wheels of Conversation served as analyzers of the functioning of the service network and the flows in primary care work and broke a diagnostic triage logic.

KEYWORDS: Family Health Support Center; Narratives; Healthcare work; Psychology; Childhoods. 


\section{Introdução}

Chovia muito e a van da prefeitura sacudia a cada buraco pelo qual passava, dando a sensação de apreensão ao entrar naquele bairro: uma estrada longa cujos desvios lembravam um labirinto - preocupação em não saber como sair dali. (Diário de Campo)

Embrenhar-se por um território desconhecido nos convoca a sair do comum, abrindo-se para o inesperado, permitindo-se o olhar atento para os efeitos que essa entrada desperta em nós e aquilo que despertamos no campo. Seja esse território um bairro com sua população e seus serviços ou as formas como as relações são vividas e construídas. No início, o desconhecido, dentre um de seus efeitos, desperta o medo, o temor de não saber como agir, de perder-se. Ao longo do processo, tornando-se familiarizado e pertencente, outra questão vai tomando forma: como seguir produzindo estranhamento naquilo que virou rotina, sem que se torne a produção de verdades absolutas e inquestionáveis?

O presente trabalho refere-se ao mergulho no território proporcionado pela A tenção Básica quando os trabalhadores saem de seus espaços conhecidos, adentrando-se em uma determinada região, encontrando-se com sua população, com os serviços, com as características que singularizam territórios e sujeitos e construindo-se como equipe.

Este artigo é resultado, também, do encontro entre diferentes atuações que congregam saberes: a atuação de uma das autoras como psicóloga em uma equipe do Núcleo de Apoio à Saúde da Família (NASF) recém-implantado e o desenvolvimento de uma pesquisa-intervenção a partir dessa prática como dissertação de mestrado (Alaion, 2017). Atuar como psicóloga a partir do lugar de pesquisadora e pesquisar a partir do trabalho que se constrói cotidianamente na Atenção Básica exigiram considerações metodológicas relativas à composição desses papéis.

Tendo em vista a preconização de que a Atenção Básica se constitua e se fortaleça como a principal porta de entrada dos usuários na rede de serviços de saúde a partir da proximidade com o território deles, bem como seja responsável pelo acompanhamento longitudinal desses usuários, criou-se a Estratégia Saúde da Família (ESF), que tem por objetivo expandir, qualificar e consolidar a Atenção Básica no país (Ministério da Saúde, 2012). Nessa mesma perspectiva, criaram-se os Núcleos de Apoio à Saúde da Família (NASF) para apoiar o trabalho realizado pela ESF, atuando como corresponsáveis pelo cuidado dos sujeitos em seus territórios e na rede de serviços (Ministério da Saúde, 2008, 2009, 2014). Conforme a diretriz política, as equipes de NASF são implantadas e organizadas de acordo com as demandas constituídas em cada território, assim, o rol de profissionais possíveis para compor uma equipe é escolhido a partir de uma análise do território feita pela secretaria de saúde; não se sabe quais os critérios utilizados para essa decisão. As estratégias da Atenção Básica, como a ESF e os NASF, baseiam-se na prerrogativa de fortalecer cada vez mais as ações em saúde com a população em seu território, a fim de que essas sejam pensadas e organizadas visando a atender as necessidades de saúde dos usuários dos serviços (Ministério da Saúde, 2008, 2009, 2012a, 2014).

Este artigo versa sobre as necessidades que se estabeleceram e as ações desenvolvidas no processo de construção de um NASF, relativas às crianças moradoras de um território. Essas ações, como veremos, assim que são formalizadas, tornam-se parte de uma rede com suas cristalizações e derivas ao mesmo tempo em que, também, uma oportunidade de colocar em análise essa rede. 
A partir de uma posição sobre o cuidado em saúde focada na relação usuário-trabalhador e utilizando como material de análise os diários de campo e a escrita de narrativas construídas no processo desta pesquisa-intervenção, contextualizaremos o território e a implantação da estratégia desenvolvida - a Rodinha de Conversa -, e daremos ênfase a uma metodologia de escrita narrativa que evitasse que nosso objeto - a construção das Rodinhas de Conversa - fosse capturado por discursos prescritivos.

\section{Cuidado em saúde: trabalhadores e usuários na construção do cuidado}

Ao iniciarmos o texto apontando que a Atenção Básica e suas estratégias visam a promover ações de saúde para um cuidado integral dos usuários do serviço, abre-se a seguinte questão: como cuidar?

As ações de saúde só são possíveis e efetivas se corresponderem àquilo que os usuários demandam. Ao pensarmos sobre as necessidades de saúde dos usuários, Cecílio (2001) aponta que, "quando alguém procura um serviço de saúde, está trazendo uma 'cesta de necessidades de saúde', que caberia à equipe ter a sensibilidade e preparo para decodificar e saber atender da melhor forma possível” (p. 4). Trata-se de uma cesta com necessidades singulares para as quais não há direcionamento a priori sem que façamos essa decodificação juntamente com o usuário.

Assim, os usuários chegam aos serviços com uma demanda não inteiramente explícita, cabendo aos trabalhadores, no momento desse encontro, compreender aquilo que os usuários almejam e produzir, conjuntamente, uma dada ação para contemplá-los. Entretanto, da mesma maneira que os usuários chegam com suas cestas de necessidades (construídas social e afetivamente, com histórias e significados diversos, medos e expectativas), os trabalhadores também carregam suas bagagens (formação acadêmica, histórias e crenças pessoais) para esse encontro.

A esse respeito, Merhy (2013) ressalta que, no campo do trabalho em saúde, o momento do encontro entre trabalhadores e usuários em que se dá a produção de cuidado é intercessor: "há a produção de um lugar situacional em ato, que quando cessa, cessa a relação intercessora” (Merhy, 2013, p. 253). É esse momento do encontro, entre trabalhadores e usuários, que Merhy (1997, 2002) e Merhy et al. (1997) nomeiam como o trabalho vivo em saúde, um trabalho instituinte e em processo de construção, em contraposição ao trabalho morto, instituído, produto de um trabalho vivo anterior, como, por exemplo, os equipamentos e instrumentos, que, no momento de sua fabricação, possuíram uma dimensão viva, mas que, agora, prontos, são expressão de um trabalho morto. O trabalho em saúde nunca poderá ser completamente capturado pelo trabalho morto (Merhy, 1997, 2002; Merhy et al., 1997), visto que o trabalho vivo se realiza imediatamente na produção, algo sempre instituinte - "o ato de produção no trabalho em saúde se dá no imediato ato de consumir" (Merhy, 1997, p. 110).

Ainda sobre o trabalho em saúde, Merhy et al. (1997) irão apontar que nele há diferentes tecnologias, compreendidas no que diz respeito não apenas a um equipamento tecnológico, mas também a um saber-fazer e a ir fazendo na ação. Essas tecnologias são de três ordens: leves, que dizem respeito ao campo relacional, à produção de vínculo, 
ao acolhimento; leve-duras, relacionadas aos saberes estruturados, como, por exemplo, a clínica psicológica; duras, como, por exemplo, os equipamentos tecnológicos, as regras, os exames de imagem.

Merhy (2013) alerta que, "quando as tecnologias duras e leve-duras se sobressaem às tecnologias leves, corremos o risco de fazer desaparecer o usuário nessa construção conjunta do ato cuidador" (p. 256). O predomínio do uso de tecnologias duras e leve-duras enfraquece as ações de cuidado nos serviços. São as tecnologias leves que conferem vida ao trabalho em saúde, permitindo ao trabalhador operar sob as singularidades de cada realidade vivida pelos usuários com os quais se encontra, dando sentido, assim, para as demais tecnologias que compõem o seu trabalho (Merhy \& Feuerwerker, 2014).

Ao criar estratégias para fortalecer a Atenção Básica, como responsável pelo cuidado longitudinal dos usuários dos serviços da rede de saúde, visa-se à promoção do cuidado integral, buscando-se enfrentar as fragmentações e rupturas que desconsideram as necessidades dos usuários. Um agir implicado no cuidado ao outro reconhece o trabalhador como uma das partes desse cuidado, não a única.

Assim, compreendendo o trabalho em saúde a partir dessas reflexões, neste trabalho, abordamos a construção de uma ação dentro da Atenção Básica, a partir do encontro entre trabalhadores da saúde (USAFA e NASF) e uma população em que as questões da infância ganharam relevo.

\section{A infância na construção de um NASF}

A experiência disparadora deste trabalho refere-se à implantação de três equipes do NASF, no ano de 2015, em um município litorâneo da Baixada Santista. A coordenação de Saúde Mental da região vislumbrava, com tal implantação, efetivar ações dentro da Atenção Básica. Portanto, nesse município, o trabalho do NASF emergiu atravessado e alimentado pelas demandas do setor de Saúde Mental: discutir a patologização e a medicalização da vida, os excessivos encaminhamentos para avaliação psiquiátrica de crianças e adultos, promover ações de prevenção e conscientização no território, entre outras. A equipe constituiu-se for temente com essas funções nos profissionais.

As três equipes de NASF desse município foram igualmente contempladas com profissionais da psicologia, serviço social, pediatria e ginecologia, e diferiam no fato de uma equipe contar com fisioterapeutas, outra com uma educadora física e, outra, com nutricionista, de acordo com as demandas das regiões em que estavam referenciadas. Por se tratar da modalidade de NASF tipo 1, cada equipe apoiava de 5 a 9 equipes de ESF alocadas em 3 ou 4 Unidades de Saúde da Família (USAFA) localizadas em três regiões distintas do município que englobavam um número diferente de bairros, conforme as diretrizes que regulamentam o funcionamento do NASF (Ministério da saúde, 2012b).

A equipe de NASF foco deste trabalho apoiava quatro USAFAs, correspondendo a quatro bairros - A, B, C e D - com características populacionais, territoriais e socioeconômicas distintas; um deles, o bairro C, chamava atenção pela situação de vulnerabilidade social em que sua população vivia.

Esse bairro estava localizado na região portuária, cercado por mar, mangue e terminal de carga, tendo se formado pela apropriação irregular de terra de seus primeiros moradores, em sua maioria pescadores, no meio do manguezal e fazendo margem com o mar. 
Esse território possuía apenas uma entrada e uma saída, uma avenida de paralelepípedos, cortada pela linha do trem e aromatizada com a decomposição dos grãos que caíam pelo caminho.

A localização e a forma de acessar o bairro imprimiram efeitos no modo como a população se percebia e se relacionava com o restante da cidade e com os equipamentos da rede. Os moradores desse bairro carregavam a insígnia da dificuldade: tudo exigia muitos esforços, sair do bairro e transitar pela cidade implicava conseguir se deslocar de um lugar quase inacessível, com meios de transporte escassos; um lugar apartado. Assombrados pelo perigo da desapropriação e pela falta de interesse em investimentos que revertessem em melhoria na qualidade de vida, os moradores viviam as marcas de pertencer a um bairro tratado com descaso. Um bairro com aproximadamente 12 mil habitantes que tinha uma única escola e a USAFA como serviços públicos.

No contato entre NASF, USAFA e o bairro C foi possível perceber os olhares destinados a essa população interferindo diretamente no trabalho a ser realizado pela Atenção Básica. A unidade também sofria efeitos do desinteresse no bairro: operava em locais alugados, sem sede própria, muitas vezes com uma infraestrutura aquém do necessário, improvisando-se em imóveis residenciais disponíveis no bairro; o número de Agentes Comunitários em Saúde (ACS) era incompatível com a população do bairro, assim como o número de equipes de ESF que não respeitava o preconizado na política; pela região em que estava localizada, não se encontravam médicos disponíveis para adentrar no bairro, marcado pela atuação do tráfico de drogas, pelo saneamento básico precário e pela extrema pobreza.

A equipe da USAFA que contava, naquele momento, com dois médicos, uma enfermeira, duas auxiliares de enfermagem, um dentista, uma auxiliar de saúde bucal e quatro ACS - sendo que um estava em desvio de função, ou seja, não atuava como ACS no momento -, trabalhava com o número de equipes e profissionais inferior ao que é previsto para uma população com esse número de habitantes. A estimativa da Política Nacional de Atenção Básica (PNAB) (Ministério da Saúde, 2012b) é de uma equipe para cada 4 mil habitantes, sendo cada uma composta por no mínimo um médico, um enfermeiro, um auxiliar de enfermagem e ACS, podendo ser ampliada com a equipe de saúde bucal (dentista, auxiliar e/ou técnico em saúde bucal). A unidade estava atendendo três vezes mais do que lhe cabia.

A unidade de saúde era o local ao qual todos recorriam: um local próximo e acessível - tanto pela localização, dentro do território, como pelas dificuldades em conseguir acessar os serviços que ficavam fora do bairro. A equipe da unidade estava sempre trabalhando com as urgências e, tentando tudo acolher, acolhia-se precariamente.

A urgência dificultava o estabelecimento de parcerias. Quando a equipe do NASF adentrou essa região, em meio à necessidade de sua própria construção de identidade, aproximou-se pelas beiradas, inserindo-se em atividades e ações que já existiam na agenda da unidade de atenção básica: antes de propor qualquer novidade, era preciso mergulhar naquela realidade. Havia um espaço aberto semanalmente para a população, a Roda de Conversa, com duração de aproximadamente uma a duas horas, para compartilhar, refletir e discutir questões relativas à Saúde Mental. Essa ação fora desenvolvida a partir de uma intervenção do Setor de Saúde Mental do município em 2014: avaliou-se que havia longas filas de espera para avaliações psiquiátricas e que a grande maioria desses encaminhamentos era relativa a questões que poderiam ser acompanhadas na própria Atenção Básica. Assim, as Rodas de Conversas constituíram-se, no município, como espaço de acolhimento de questões de Saúde Mental e avaliação da necessidade de encaminhamento 
e acompanhamento para os Centros de Atenção Psicossocial (CAPS). Elas foram implantadas em todas as unidades de saúde da rede, sendo organizadas pelos trabalhadores de saúde da unidade (ACS, enfermeiros, médicos, farmacêuticos) e contando com o apoio do profissional de Saúde Mental, podendo ser do NASF ou o psicólogo da prefeitura.

Essa atividade foi inserida na agenda habitual da unidade em que a pesquisa foi realizada, possibilitando o encontro entre os trabalhadores de saúde e os usuários do serviço para conversas sobre temas do campo da Saúde Mental compreendidos como questões de saúde. Era um momento de grande intensidade: para os trabalhadores que ouviam e para os usuários que compartilhavam aquilo que os desassossegava. Às vezes, a sala enchia-se de pessoas e relatos que, naquelas quase duas horas, escancaravam o sofrimento daquela população. Marcas de histórias permeadas por dor, precariedades e violências. Diante de tantas mazelas, abandono e silenciamentos, a população adoecia.

Seus relatos inquietavam, tanto por seu conteúdo quanto pelo apelo que carregavam: o que fazer com esse sofrimento? Qual o nome para aquilo? Existiria remédio que desse conta? Essas questões afetavam fortemente os trabalhadores: que destino dar àquilo que escutavam? Encaminhar para o CAPS? Prescrever medicação?

Entre tantas inquietações despertadas, uma foi ficando cada vez mais evidente: as crianças que apareciam nas Rodas de Conversa - nas falas e, também, fisicamente. Eram trazidas por seus responsáveis e encaminhadas pelos médicos da unidade e pelas escolas. Nos relatos dolorosos dos adultos na Roda de Conversa, as vidas das crianças ficavam em segundo plano. Ponderamos a possibilidade de construir um espaço configurado de maneira a dar conta das especificidades que a infância comporta.

Propusemos Rodinha de Conversas para Crianças: um espaço de encontro entre os trabalhadores do serviço, as crianças e suas famílias, destinado a discutir as questões de saúde mental na infância. Um espaço para ouvir, falar e brincar juntos. Depois de alguns meses, estabeleceu-se o seguinte formato: encontros de uma hora, sendo que em uma semana os trabalhadores da saúde se encontravam com as mães, pais e responsáveis e, na outra semana, com o grupo de crianças. A Roda de Conversa que já existia na agenda continuou com a sua formatação e frequência, mas a partir daquele momento as crianças não permaneciam naquela conversa, já que se criara um espaço para elas.

A Rodinha de Conversa, objeto deste trabalho, construiu-se como uma estratégia de cuidado à infância na Atenção Básica e de enfrentamento à fragmentação desse cuidado na rede de serviços. A seguir serão apresentados os recursos metodológicos utilizados para compreender os efeitos da constituição das rodinhas como estratégia interventiva.

\section{Uma pesquisa-intervenção, um trabalho pesquisa}

A concomitância entre estar como trabalhadora em saúde na Atenção Básica e pesquisadora na pós-graduação inaugurou questões para a pesquisa e provocou ações e reflexões sobre o que se produzia no cotidiano de um serviço de saúde. A cartografia (Guattari \& Rolnik, 1986/2013; Kastrup, 2008; Passos, Kastrup, \& Escóssia, 2014; Passos, Kastrup, \& Tedesco, 2014; Rolnik, 2006) fez-se como possibilidade metodológica em que os processos de constituição das ações no cotidiano do NASF foram campo de pesquisa. Nesse sentido, os encontros, as propostas de ações e seus efeitos, e desvios ao longo do 
percurso, tornaram-se processos a serem acompanhados e investigados (Kastrup, 2008; Pozzana \& Kastrup, 2014). Diante desse cenário em que os papéis de trabalhadora e pesquisadora coexistiam, criamos instrumentos e estratégias para organizar o que se experienciava a partir desses lugares e discutimos questões com os profissionais envolvidos na construção da Rodinha de Conversa que acompanharam a proposta e o percurso da pesquisa. Destacaremos, neste texto, um dos instrumentos desenvolvidos, referente à escrita.

A investigação sobre um fazer demandou uma estratégia de escrita-registro que pudesse abarcar elementos da experiência do encontro entre trabalhadores e usuários de um serviço em saúde que fosse capaz de nomear a processualidade na produção do cuidado em seus aspectos relacionais e de não apenas descrever um produto.

Uma escrita que permitisse a experiência falar: poder falar de dentro dela, e não sobre ela (Passos \& Kastrup, 2014). As formas narrativas constituíram-se como uma metodologia durante o processo da pesquisa.

Essa escrita apreende movimentos e processos e foca a construção da pesquisadora-trabalhadora. Ao iniciar a pesquisa, o pesquisador parece como uma forma definida fora do território da pesquisa, mas, ao longo do processo e dos encontros, vai deformando-se, oportunizando intenções e expectativas que servem como analisadoras do processo (Kastrup, 2008). No próprio ato de pesquisar formam-se o pesquisador e a pesquisa (Barros \& Silva, 2014; Pozzana, 2014), assim como o trabalho vivo em saúde também ocorre apenas em ato - no momento do encontro entre o trabalhador de saúde e o usuário do serviço (Merhy, 1997, 2002; Merhy et al, 1997). Ao ressaltar a palavra ato, pretendemos dar relevo à pesquisa como produtora da realidade que é pesquisada.

Como recurso metodológico para intensificar a escrita como produtora da realidade, utilizamos diários de campo em que registramos os cenários vividos. Eles serviram de material para a construção de três narrativas - de Dona Ana, do bairro e da Rodinha de Conversa - que subsidiaram a criação do percurso narrativo apresentado neste artigo. Durante a pesquisa, os diários de campo e as narrativas exigiram várias versões à luz da leitura do grupo de orientação (formado pela orientadora da pesquisa e por estudantes de pós-graduação) em que os estranhamentos de trechos escritos de forma romantizada, exteriorizada e estereotipada eram nomeados. As discussões coletivas desses textos permitiam advir algumas forças em jogo nas escolhas realizadas sobre o que e como narrar aquilo que era vivido em campo (Carvalho \& Costa, 2011; Casetto, 2013), tomando o cuidado de evidenciar, nas situações de escrita, uma postura prescritiva e julgadora em que se adjetivavam pessoas e fatos e se formalizava um tom de verdades absolutas e inquestionáveis.

A escrita das narrativas neste trabalho revela-se como uma escrita-ato que dá visibilidade para as forças em jogo na construção da Rodinha de Conversa e elege formas de escrever os processos de construção dessa estratégia que incluam a implicação dos atores da rede nessa ação. Informações sobre o bairro, a história de Dona Ana e a construção das Rodinhas de Conversa, escritas em forma de narrativas, inspiraram o percurso narrativo apresentado a seguir. 


\section{Percurso narrativo: a Rodinha de Conversa como espaço de disputa}

Um dia, tão cansada e desacreditada, chorando no ônibus, vinha conversando com Deus: "Manda alguém para me ajudar! Meu pai tá aí e nem olha para mim...". Ela vai contando com tanta energia e fé, que eu me percebo orando, quase implorando junto com ela: "Meu Deus, olha para essa mulher!"(Diário de Campo)

Dona Ana (todos os nomes das personagens foram substituídos, a fim de evitar a sua identificação), "senhora" de seus 38 anos, ao contar sobre sua vida, implorava e despertava sentimentos de confusão, de tristeza, de expectativa por aquilo que estava por vir; os fatos pareciam cenas de filme. Aquela mulher, com tantos dissabores e reviravoltas em sua vida, carregava em seu corpo marcas de quem muito vivera, de "uma senhora", não pelos anos que estava no mundo, mas pela intensidade e violência de tudo aquilo.

Dona Ana fora uma das participantes do grupo de pais e responsáveis de crianças que participavam da Rodinha de Conversa; estava lá pela neta de seis anos - Maria Helena, menina danada, cheia de vida -, para quem a escola buscava um diagnóstico, uma ajuda para lidar com aquela "menina difícil". O grupo era formado por famílias e crianças que faziam o impossível para sobreviver diante dos obstáculos impostos pela vida e por trabalhadores de serviços que lidavam com a árdua tarefa de fazer o possível com os recursos disponíveis.

A tarefa de encontrar as palavras para descrever o processo de construção de nossa ação no território carregou um permanente esforço na construção de cada frase, em que a dor da vida vivida nesse contexto de precariedade passava a ser de nossa responsabilidade. A narrativa de Dona Ana foi a primeira a ser escrita no percurso da pesquisa - como alguém poderia ter vivido tudo aquilo? E como tudo aquilo poderia caber em uma escrita? Uma mulher que nasceu no norte do país, casara-se aos treze anos, vivendo com esse companheiro por dez anos, com quem tivera seus três filhos (duas meninas e um menino). Esse primeiro relacionamento fora marcado por agressões físicas e abandono. Desnorteada, seguiu de carona em carona em direção ao sudeste, em um vai e vem encontrando naquela cidade litorânea um local para fazer morada e recomeçar. Muitos foram os recomeços na história de Dona Ana, que viveu situações de miserabilidade, fez da rua sua morada e do álcool seu consolo, foi presa por falsificação de documentos e sentia que estava enlouquecendo. Viveu dores que nenhuma mãe espera viver: seu companheiro abusara de uma de suas filhas; viu seu filho ser preso injustamente e lutou para provar sua inocência; acompanhou sua filha adoecer e temeu perdê-la. Por muitas vezes, se viu sozinha, sem amigos, abandonada, diz ela, até mesmo por Deus. Ao longo de sua vida, se deparou com a ideia da morte: uma possibilidade diante de tudo que era difícil e, ao mesmo tempo, um grande medo de partir e deixar sua neta sozinha. No relato, os serviços da rede - de educação, saúde, assistência social e habitação - parecem ausentes. Dona Ana, de família pobre, tem uma vida desacreditada, cuja sobrevivência a torna uma heroína.

Sobrevivência parece ser a marca dos que moram em sua comunidade. O bairro em que Dona Ana se estabeleceu, território de atuação da USAFA, exige, de quem o habita, resistência para seguir existindo. O lixo e o forte odor impregnam os sentidos daqueles que adentram aquele território pela primeira vez e coexistem com a circulação de animais e crianças seminuas. Um labirinto de ruas e imagens que desperta nos visitantes o temor de perder-se por ali; nos moradores, a única estrada parece delimitar até onde podem ir, 
nos deslocamentos físicos e afetivos para dentro e fora daquele lugar. Sentem-se estrangeiros ao sair e, no bairro, esquecidos por todo o restante da cidade, parecem fazer parte de um lugar que não deveria existir; suas moradias precárias eram frutos das invasões daquele espaço, em que os interesses políticos e econômicos caminham longe do desejo de fazer melhorias. O destino anunciado era a desapropriação. O Estado, quando atuava, fazia-se presente como uma mão de ferro, intervindo naquelas famílias que eram vistas - elas! como violadoras de direitos ou não protetivas, desconsiderando a desproteção do próprio Estado a elas ao negar-lhes o que lhes é direito.

Nesse lugar, a escola e a unidade de saúde, únicos serviços públicos do bairro, seguiam sendo lugares de lutar pela vida. Dona Ana, assim como muitos moradores, via nesses espaços e em seus trabalhadores uma possibilidade de fortalecimento e enfrentamento às dificuldades que se faziam presentes ali: a atuação maciça do tráfico de drogas, da exploração sexual infantil, da violência doméstica, da precariedade no saneamento básico e moradia, entre tantas outras. Ela confiava nessa unidade de saúde, porque em um de seus tantos momentos de dificuldade, ao ficar gravemente doente, encontrou conforto em uma das enfermeiras. E, quanto à escola, nela depositava a esperança de que, por meio do estudo, sua neta poderia ter um futuro melhor, algo que ela e seus filhos não puderam vislumbrar.

É nesse contexto, no qual o difícil se faz presente, que o NASF é convocado a agir. Nos encontros proporcionados pela Roda de Conversa, em que os moradores vão compartilhando suas dores e lutas, as crianças apareciam em suas falas, como aquelas que também estão em situações difíceis e que mobilizam a família por algo disparado, muitas vezes, na vida escolar. Compondo com a realidade do território em que tudo parece faltar, principalmente um espaço que seja destinado à ocupação das crianças, elas deixam de ser apenas personagens de um relato e passam a circular ativa e vivamente pelos encontros na unidade de saúde, anunciadas como portadoras de problemas a serem resolvidos, como a neta de Dona Ana, descrita pelas professoras da escola como uma menina agitada, que comia lápis, destruía seus materiais e brigava com as crianças. O que fazer com essa menina? Uma pergunta que angustiava as professoras da escola, a avó e os trabalhadores da saúde.

Com a entrada das crianças em cena - trazidas nos relatos da família ou ao vivo e a cores -, foi se tornando necessário tempo-espaço de escuta da infância. Construiu-se a Rodinha de Conversa, inspirada por aquela Roda já em andamento. Duas, cinco, dez ou até mais crianças compunham o encontro com os trabalhadores. Correria, gritos, empurrões, movimentos... não era fácil! Sentar, ouvir e pontuar, como nos encontros com os adultos, não era possível. Esses encontros exigiam outro corpo, diferente do corpo sentado que fala. E esse corpo necessário era tido, na equipe, como sendo o corpo-de-psicóloga. Como se esse fosse o único corpo que detinha esse saber-fazer, como se nenhum outro fosse capaz, revelando os receios dos demais trabalhadores sobre como agir nessas cenas. Se a psicóloga não estivesse presente, considerava-se que era melhor cancelar os encontros. A Rodinha incitava, nas crianças, a vontade de brincar e a brincadeira desestabilizava os trabalhadores da unidade.

Tagarelices, andanças, movimento, barulho em uma sala de pouco mais de 12 metros quadrados com duas pequenas janelas e paredes rosa... as crianças foram se apropriando daquele espaço cada uma à sua maneira: um garoto, dito danado, que denominou aquele lugar de seu "clubinho", dizia "aqui tenho médicos só para mim!", assim como seu irmão, com deficiência que passava por diversos acompanhamentos. Um tempo-espaço em que ser irmão de uma criança que requer muitos cuidados revelava que essa não é uma situação de fácil manejo. 
Éramos uma Unidade de Saúde que organizava um momento para estar com essas crianças que, nas falas dos profissionais da escola e de suas famílias, apresentavam problemas. As crianças verbalizavam que tinham dificuldades a serem sanadas. Nossa aposta era que criar formas de estar com elas poderia agir no lugar constrangido a que iam sendo submetidas no atravessamento de vários discursos.

A Roda de Conversa, em que participavam os responsáveis, era composta majoritariamente por mulheres (mães, avós e tias). A mãe do menino que queria ter médicos só para ele compartilhava as angústias em relação às travessuras do filho em casa, na rua e na escola, temendo que um dia fosse se tornar uma má pessoa, um bandido. Essa mãe, encarregada sozinha do cuidado com os filhos, sendo que um deles precisava de muitos atendimentos, disse um dia, como se confessasse, que havia cogitado dar seus calmantes para que esse filho, que participava da Rodinha, ficasse mais tranquilo.

Essas mulheres sofriam na lida com os pequenos e as solicitações, de familiares e da escola, eram para que encontrássemos soluções para os comportamentos e dificuldades de suas crianças. Angustiavam-se, também, com medo de que tudo o que sonharam para os seus filhos não se concretizasse e que fossem atraídos pelo tráfico, que se fazia presente e atuante em cada esquina. Para muitas dessas famílias, os estudos eram a oportunidade de seus filhos traçarem um futuro diferente do que seus pais tiveram. Assim, quando as crianças pareciam não corresponder ao que a escola demandava, seus sonhos se tornavam ameaçados.

Dona Ana, como outras mães, avós e tias, procurava encontrar formas para solucionar essas questões. A Rodinha de Conversa passou a comportar as expectativas das famílias, da escola e das crianças para solucionar o que se configurava como um problema. Essas crianças iam chegando com rótulos, nomes prontos e futuros definidos. À medida que os encontros ocorriam, mais e mais encaminhamentos da escola chegavam, tensionando a relação saúde e educação, já muito discutida na literatura e em experiências em que elementos na e da história são refletidos visando a ampliar a análise sobre o processo de construção das demandas (Machado, Lerner, \& Fonseca, 2017; Patto, 1987/2015). A Rodinha foi sendo tomada como uma oportunidade para conseguirmos pautar a infância na rede de serviços, na mesma rede em que a infância se constitui como problemática. Nesse sentido, havia o esforço, no trabalho da Rodinha, de não sermos capturados pelos nomes, diagnósticos e destinos profetizados a essas crianças. Um esforço que dizia respeito à compreensão de que nosso objetivo não era nomear um funcionamento; a ideia era fazermos da Rodinha uma proposta de estar com as crianças de maneira não prescritiva.

Nos encontros, as crianças agiam conforme seu jeito de estar no mundo: tagarelas e quietinhas, emburradas e sorridentes, atentas e questionadoras... umas gostavam de ficar perto ou no colo dos trabalhadores, havia as que, em certo dia, enfureciam-se quando contrariadas e arremessavam os brinquedos, ou aquelas que nada diziam, nem faziam, apenas permaneciam ali. Desenhar, ler histórias, bater cartas, carrinho, boneca, mímicas... As brincadeiras iam surgindo de acordo com o dia: Danilo, 6 anos, tagarelava enquanto explorava toda a sala; Maria Helena preferia desenhar próximo a um trabalhador; André, 10 anos, e Cristóvão, 9 anos, gostavam de falar sobre tecnologias; Letícia, 7 anos, preferia as bonecas e conversar, enquanto o seu irmão Jefferson, 5 anos, gostava de falar sobre super-heróis e, quando contrariado, fazia bico; assim como os irmãos Bruno, 7 anos, e Cássio, 4 anos, que colocavam a sala abaixo quando algo não ocorria do jeito deles...

Crianças de todos os jeitos, com interesses diversos. Trabalhadores que reaprendiam a brincar, enquanto buscavam compreender os movimentos de cada criança. Nos dias em 
que o encontro fervilhava de gritos e brinquedos para todos os lados, palavras de controle se formavam nas gargantas dos trabalhadores cansados e irritados - Não corre! Não grita! Não empurra! -, e surgiam, mais facilmente, os nomes de diagnósticos: "Danilo tem hiperatividade, com certeza!", “Cássio, daquele jeito, só pode ter Transtorno OpositivoDesafiador (TOD)!”, “Como a mãe do Bruno aguenta tanta birra?”, "Alguém percebeu que o Cristóvão só fala da mesma coisa o tempo todo e faz umas coisas estranhas com a mão? Não será autismo?”.

Era necessário que o cansaço baixasse para que esses rótulos pudessem ser dissolvidos. Trabalhar com as crianças exigia problematizarmos aquilo que, em nós, transformava uma vida em um diagnóstico. Isso se dava nos espaços de reflexão sobre os encontros em que considerávamos os elementos da história dessas crianças e discutíamos as disputas em jogo na forma de funcionar e de pensar da equipe. A costura que íamos fazendo em nossas discussões visava a preservar as singularidades.

\section{O que não se conclui}

Da mesma maneira que transitar por aquele bairro-labirinto despertava receios em perder-se entre suas ruelas, dificuldades e vidas, a construção de uma ação com crianças nesse território e a escrita dessa experiência carregavam uma pergunta-desassossego: que forma de controle produzimos e reproduzimos em nossas propostas? As Rodinhas de Conversa foram criadas por um incômodo - a ausência de um lugar para acolher questões de saúde das crianças na agenda daquela unidade -, mas, assim que ela se pôs a funcionar na rede de serviços (saúde, assistência social e educação), inauguraram-se problemas referentes a essa rede.

Aos poucos a Rodinha foi sendo tomada, na rede de serviços, como um espaço de triagem para outros serviços de saúde, comportando uma expectativa do campo da saúde em responder qual seria o lugar ideal para atender determinadas demandas. Nas reuniões e conversas com os profissionais de diferentes serviços da rede, sempre tínhamos o que dizer a partir das reflexões desse trabalho, que não se limitava a produzir prescrições e encaminhamentos. Por participarmos de um tempo-espaço de proximidade com as crianças, éramos tomados como aqueles que poderiam definir melhor os encaminhamentos. Discutia-se a viabilidade de esse espaço vir a compor o fluxo da Linha do Cuidado ao Transtorno do Espectro do Autismo (TEA) que estava sendo implementada no município, tornando-se, assim, uma das etapas possíveis de investigação dos sinais do TEA. Essa possibilidade dialogava com as expectativas de famílias, crianças, trabalhadores e serviços e fomentava a criação de Rodinhas de Conversa em unidades de saúde de outros territórios. Havia um permanente esforço em manter a Rodinha como um espaço do brincar, do encontro entre trabalhadores da saúde e crianças e para que aquele lugar não perdesse seu caráter instituinte (lugar de risos, brincadeiras, invenções), não se tornasse uma tecnologia para triar e encaminhar. A regra: o brincar, os desejos, os sonhos e os medos de cada criança e família não podiam ser obscurecidos por diagnósticos e prescrições.

A constante reflexão coletiva sobre os procedimentos nas discussões entre os profissionais envolvidos no trabalho em saúde reflete uma lógica pautada pelo cuidado e alerta ao perigo de capturar e reduzir os usuários a um nome ou encaminhamento. Cuidado presente, também, na construção da escrita das narrativas na pesquisa. As discussões coletivas 
dos textos estiveram atentas a formas de pensar e escrever prescritivas que tendem a cair nas malhas do já pensado. Para que as vidas pudessem emergir nas narrativas sem que nos tornássemos prescritores e julgadores de como essas vidas deveriam ser, foram necessárias várias leituras coletivas do material e muitas reescritas.

A escrita das narrativas surgiu como uma estratégia metodológica alinhada a uma ética da produção do cuidado, dentro da Atenção Básica e também na escrita acadêmica, proporcionando que o processo de construção das ações tornasse visíveis os desvios, os entraves, as reorganizações e os efeitos no cruzamento de diferentes linhas: o incômodo que suscita o desejo por Rodinha; essa proposta em ação; os personagens que a constituem, com suas bagagens, expectativas e receios; as reverberações nos demais equipamentos da rede de serviços e as demandas e problemas que surgem a partir dela. As narrativas permitiram tensionar e dissolver formas instituídas, possibilitando vislumbrar as forças que compõem essas formas e evidenciando que o escritor também cria o mundo que escreve. "Esse modo de dizer torna o dito e as tensões presentes na construção de um saber-fazer inseparáveis, ou seja, enquanto a narrativa se dá, também constrói um saber-fazer pautado na experiência” (Alaion, 2017, p. 104). A narrativa de Dona Ana, a primeira a ser escrita, nos ensinou isto: ela não era um a priori da pesquisa, o encontro com sua história e a narrativa construída a partir dele acionaram relações não pensadas e fazeres, até então, não formalizados. 


\section{Referências}

Alaion, A. R. (2017). Narrativas de um trabalho em saúde na Atenção Básica: território, NASF e produção do cuidado. Dissertação de Mestrado, Programa de Pós-graduação em Psicologia, Universidade de São Paulo, SP.

Barros, M. E. B. \& Silva, F. H. (2014). O trabalho do cartógrafo do ponto de vista da atividade. In E. Passos, V. Kastrup, \& S. Tedesco (Orgs.), Pistas do método da cartografia: a experiência da pesquisa e o plano comum (Vol. 2, pp. 128-152). Porto Alegre: Sulina.

Carvalho, E. M. \& Costa, E. L. (2011). As potências da narrativa. In K. J. M. Lopes, E. M. Carvalho, \& K. S. A. L. Matos (Orgs.), Ética e as reverberações do fazer (pp. 60-73). Fortaleza: Edições UFC.

Casetto, S. J. (2013) A narrativa na clínica comum. In A. A. Capozzolo, S. J. Casetto, \& A. O. Henz (Orgs.), Clínica comum: itinerários de uma formação em saúde (pp. 277-281). São Paulo: Hucitec.

Cecílio, L. C. (2001). As necessidades de saúde como conceito estruturante na luta pela integralidade e equidade na atenção em saúde. In R. Pinheiro \& R. A. Mattos (Orgs.), Os sentidos da integralidade na atenção e no cuidado à saúde (pp. 113-126). Rio de Janeiro: IMS; UERJ; Abrasco.

Guattari, F. \& Rolnilk, S. (2013). Micropolítica: cartografias do desejo. (12 ed.). Petrópolis, RJ: Vozes. (Original publicado em 1986)

Kastrup, V. (2008). O método da cartografia e os quatro níveis da pesquisa-intervenção. In L. R. Castro \& V. L. Besset (Orgs.), Pesquisa-intervenção na infância e juventude (pp. 465-489). Rio de Janeiro: FAPERJ; Nau Editora.

Machado, A. M., Lerner, A. B. C., \& Fonseca, P. F. (2017). Movimentos Políticos e Discursivos em Psicologia e Educação: fragmentos de uma história. In Concepções e proposições em Psicologia e Educação: a trajetória do Serviço de Psicologia Escolar do Instituto de Psicologia da Universidade de São Paulo (pp. 12-28). São Paulo: Blucher.

Merhy, E. E. (1997). Em busca do tempo perdido: a micropolítica do trabalho vivo em saúde. In E. E. Merhy \& R. Onocko (Orgs.), Agir em saúde: um desafio para o público (pp. 71-112). São Paulo: Hucitec.

Merhy, E. E. (2002). Saúde: a cartografia do trabalho vivo em ato (3a ed.). São Paulo: Hucitec.

Merhy, E. E. (2013). Ver a si no ato de cuidar. In A. A. Capozzolo, S. J. Casetto, \& A. O. Henz (Orgs.), Clínica comum: itinerários de uma formação em saúde (pp. 248-267). São Paulo: Hucitec.

Mehry, E. E., Chakkour, M., Stéfano, E., Stéfano, M. E., Santos, C. M., \& Rodríguez, R. A. (1997). Em busca de ferramentas analisadoras das tecnologias em saúde: a informação e o dia a dia de um serviço, interrogando e gerindo trabalho em saúde. In E. E. Merhy \& R. Onocko (Orgs.), Agir em saúde: um desafio para o público (pp. 113-150). São Paulo: Hucitec.

Merhy, E. E. \& Feuerwerker, L. C. M. (2014). Educação Permanente em Saúde: educação, saúde, gestão e produção do cuidado. In A. C. S. Mandarino, E. Gallo, \& E. Gomberg (Orgs.), Informar e Educar em Saúde: análises e experiências. Salvador, Rio de Janeiro; EDUFBA; Fiocruz. Recuperado de https://static.atencaobasica.org.br/II Mostra EP/EPS-educacao saude gestao e producao do cuidado Merhy e Laura.pdf 
Ministério da Saúde. (2008). Portaria $n^{0}$ 154, de 24 de janeiro de 2008. Cria os Núcleos de Apoio à Saúde da Família. Diário Oficial da União, Brasília, DF, Brasil, Seção 1, n. 43, p. 38-40, 04 mar. 2008. Recuperado de http://bvsms.saude.gov.br/bvs/saudelegis/gm/2008/ prt0154_24 01 2008.html

Ministério da Saúde. (2009). Secretaria de Atenção à Saúde. Departamento de Atenção Básica. Diretrizes do NASF. Brasília, DF: Autor. 160 p. - (Série B. Textos Básicos de Saúde) (Cadernos de Atenção Básica; n. 27).

Ministério da Saúde. (2012a). Secretaria de Atenção à Saúde. Departamento de Atenção Básica. Política Nacional de Atenção Básica. Brasília, DF: Autor. Recuperado de http://189.28.128.100/ dab/docs/publicacoes/geral/pnab.pdf

Ministério da Saúde. (2012b). Portaria n 3.124, de 28 de dezembro de 2012. Redefine os parâmetros de vinculação dos Núcleos de Apoio à Saúde da Família (NASF)..., e dá outras providências. Diário Oficial da União, Brasília, DF: Autor. Seção 1. Recuperado de http://bvsms.saude.gov.br/bvs/saudelegis/gm/2012/prt3124_28 12 2012.html

Ministério da Saúde. (2014). Secretaria de Atenção à Saúde. Departamento de Atenção Básica. Núcleo de Apoio à Saúde da Família. Brasília, DF: Autor. 116p. - (Cadernos de Atenção Básica; n. 39).

Passos, E., Kastrup, V., \& Escóssia, L. (Orgs.). (2014). Pistas do método da cartografia: Pesquisa-intervenção e produção de subjetividade ( $3^{\mathrm{a}}$ reimpr.). Porto Alegre: Sulina.

Passos, E., Kastrup, V., \& Tedesco, S. (Orgs.). (2014). Pistas do método da cartografia: a experiência da pesquisa e o plano comum (Vol. 2). Porto Alegre: Sulina.

Patto, M. H. S. (2015). A produção do fracasso escolar: Histórias de submissão e rebeldia. (4ª ed., rev. amp.). São Paulo: Intermeios. (Original publicado em 1987)

Pozzana, L. (2014). A formação do cartógrafo é o mundo: corporificação e afetabilidade. In E. Passos, V. Kastrup, \& S. Tedesco (Orgs.), Pistas do método da cartografia: a experiência da pesquisa e o plano comum (Vol. 2, pp. 42-65). Porto Alegre: Sulina.

Pozzana, L. \& Kastrup, V. (2014). Cartografar é acompanhar processos. In E. Passos, V. Kastrup, \& S. Tedesco (Orgs.), Pistas do método da cartografia: Pesquisa-intervenção e produção de subjetividade ( $3^{\text {a }}$ reimpr., pp. 52-75). Porto Alegre: Sulina.

Rolnik, S. (2006). Cartografia Sentimental: transformações contemporâneas do desejo. Porto Alegre: Sulina; Editora UFRGS. 


\section{ALLANA RODRIGUES ALAION}

https://orcid.org/0000-0002-4057-563X

Psicóloga. Mestre em Psicologia Escolar e do Desenvolvimento Humano pelo Instituto de Psicologia da USP.

End.: Rua Thomé de Souza, 1313, Praia Grande, São Paulo, CEP: 11702-840.

E-mail: allana alaion@hotmail.com

\section{ADRIANA MARCONDES MACHADO \\ https://orcid.org/0000-0002-5513-8723}

Psicóloga, Mestre e Doutora em Psicologia Social. Docente do Instituto de Psicologia da USP.

E-mail: adrimarcon@uol.com.br

\begin{tabular}{|c|c|}
\hline Histórico & $\begin{array}{l}\text { Submissão: 15/04/2020 } \\
\text { Revisão: 16/08/2020 } \\
\text { Aceite: 17/08/2020 }\end{array}$ \\
\hline $\begin{array}{l}\text { Contribuição } \\
\text { dos autores }\end{array}$ & $\begin{array}{l}\text { Concepção: A.R.A.; A.M.M. } \\
\text { Coleta de dados: A.R.A. } \\
\text { Análise de dados: A.R.A.; A.M.M. } \\
\text { Elaboração do manuscrito: A.R.A.; A.M.M. } \\
\text { Revisões críticas de conteúdo intelectual importante: } \\
\text { A.R.A.; A.M.M. } \\
\text { Aprovação final do manuscrito: A.R.A.; A.M.M. }\end{array}$ \\
\hline Financiamento & Não se aplica. \\
\hline
\end{tabular}

